\title{
Bioavailability of lead in North Sea sediments
}

\author{
M. Kersten ${ }^{1}$ \& I. Kröncke ${ }^{2}$ \\ ${ }^{1}$ Technische Universität Hamburg-Harburg; P. O. Box 901052, D-W-2100 Hamburg 90, \\ Federal Republic of Germany \\ ${ }^{2}$ Alfred Wegener Institute for Polar and Marine Research; P. O. Box 120161, \\ $D$-W-2850 Bremerhaven, Federal Republic of Germany
}

\begin{abstract}
As part of an interdisciplinary research programme, lead contents were measured in the polychaete Nephtys spp. and in the sea-urchin Echinocardium cordatum as well as in the respective sediment fractions $<20 \mu \mathrm{m}$ taken from the Dogger Bank proper and the eastern coastal North Sea. A lower lead content was generally observed in the organisms taken from the German Bight than in those from the Dogger Bank, especially from its northeastern part. It is possible to divide both areas according to the slope found in the linear regression of lead versus total organic carbon contents in sediments, which is twice as steep for the Dogger Bank as for the eastern North Sea. This criterium points to a difference in sediment quality with regard to toxic metal contamination. The sediment quality of the Dogger Bank seems to be twice as bad compared with that of the eastern North Sea. This is in good agreement with the differences found in lead contamination of the sediment-dwelling polychaetes from both areas. The results indicate that lead is primarily accumulated by food ingestion.
\end{abstract}

\section{INTRODUCTION}

Prediction of the bioavailability and toxicity of metals in aquatic sediments is a critical component in the development of sediment quality criteria (Förstner et al., 1990). Given the importance of the sediment-water interface in controlling various biogeochemical cycles, and the potential sensitivity of the organisms living at this interface to the metals accumulating in their immediate environment, it would be of great practical interest to be able to assess the bioavailability of metals associated with a particular sediment. In fact, there are a lot of studies on the levels of contaminants in marine invertebrates that live in or feed on sediments (Campbell et al., 1988, and citations therein). They usually focus on assessing gradients in contamination within the same hydrographic system or on comparing the contamination levels of different areas. This study, as part of an interdisciplinary research project, represents such a comparative survey of two different areas within the southern part of the North Sea. It evaluates the role of sediments as a source of contaminants to organisms. In spite of the fact that field studies usually fail to provide direct proof of a causal relationship between a specific abiotic compartment and contaminant concentrations in organisms, this study attempts to provide some qualitative relationships which may elucidate the role of sediment components as a pool of bioavailable toxic metals. Lead was taken as object of this preliminary examination. 


\section{MATERIALS AND METHODS}

In August 1986, samples of sediments and of macrofauna species such as the polychaete Nephtys spp. and the sea-urchin Echinocardium cordatum were taken to analyse their trace metal content. These species were chosen because they represent different types of predators and deposit-feeders. The major region of investigation was the Dogger Bank, an offshore shallow-water area, approximately $300 \mathrm{~km}$ in length. Another area sampled was located along the eastern North Sea coast. The samples were taken with a galvanized $0.2 \mathrm{~m}^{2} \mathrm{Van}$-Veen grab. Sediments were taken from the topmost sediment layer in the middle of the grab, avoiding contact with the grab walls. From a second grab catch, sediment was quickly washed through a sieve made of a plastic frame and stainless steel mesh. Undamaged living specimen were kept in a continuous flow incubation for two days to allow them to empty their guts. They were subsequently stored frozen $\left(-20^{\circ} \mathrm{C}\right)$.

Sediments were first transferred to a 2-1 glass beaker using Milli-Q water, stirred vigorously in an ultrasonic bath for $5 \mathrm{~min}$ to disperse the fines and to disaggregate any faecal pellet flocs, and allowed to stand $\leq 5 \mathrm{~min}$ to settle the coarse and intermediate size material. The suspension, containing the fine-grained material, was then decanted to a second beaker and washed finally through a precision electroformed sieve (mesh size 20 $\mu \mathrm{m})$ made of pure nickel. Extended ultrasonic wet-sieving was thereby avoided to prevent scrubbing of coatings from the coarse-grained sediment fraction. The samples were freeze-dried and subsequently digested in an open system by boiling nitric acid prior to analysis of trace metals by graphite furnace atomic absorption spectroscopy (GFAAS). Subsamples were additionally extracted in $1 \mathrm{M} \mathrm{HCl}$ in order to get a "nonresidual" fraction of the metals. Total organic carbon (TOC) in subsamples of these sediment fractions was determined with the usual CHN-Analysator technique (Liebezeit, pers. comm.).

Specimens of Nephtys spp. were selected to give the length class 6-8 cm. Five individuals per station were pooled, freeze dried and subsequently pulverized with a plastic stick. An aliquot of about $100 \mathrm{mg}$ was used for the analytical procedure described in detail previously (Kröncke, 1987). For $E$. cordatum, the length class $3-5 \mathrm{~cm}$ was chosen for this study. Contrary to the procedure used for the other species, the calcitic skeleton of $E$. cordatum was taken for analysis. From each specimen, a piece of about $20 \mathrm{~mm}^{2}$ from the mouth region of the skeleton was broken off, pooled to give representative subsamples, solubilized by nitric acid and subsequently analysed. For all biotic and abiotic samples and stations, two independent, identically treated subsamples were analysed in order to evaluate reproducibility.

\section{RESULTS AND DISCUSSION}

\section{Lead concentrations in sediments and organisms}

The mean proportions of the $<20 \mu \mathrm{m}$ fraction, as well as median values of trace metal concentrations in sediments and organisms from both areas, the Dogger Bank and the eastern North Sea, are summarized in Table 1. The distribution of lead concentrations in the $<20 \mu \mathrm{m}$ fraction of the sandy sediments is given in Fig. 1. It shows, at first glance, 
Table 1. Median values of total lead and carbon concentration ( $\mu \mathrm{g} / \mathrm{g} \mathrm{dry}$ weight) in sediment, polychaete Nephtys ssp., and sea-urchin Echinocardium cordatum

\begin{tabular}{|lccccc|}
\hline Location & \multicolumn{2}{c}{$\begin{array}{c}\text { Sediment }<20 \mu \mathrm{m} \\
\%\end{array}$} & $\mathrm{~Pb}$ & $\begin{array}{c}\text { Nephtys spp. } \\
\mathrm{Pb}\end{array}$ & $\begin{array}{c}\text { E. cordatum } \\
\mathrm{Pb}\end{array}$ \\
\hline DoC & 5000 & 0.92 & 140 & 2.85 & 32.8 \\
Dogger Bank & 5200 & 0.85 & 154 & 1.80 & 15.0 \\
\hline
\end{tabular}

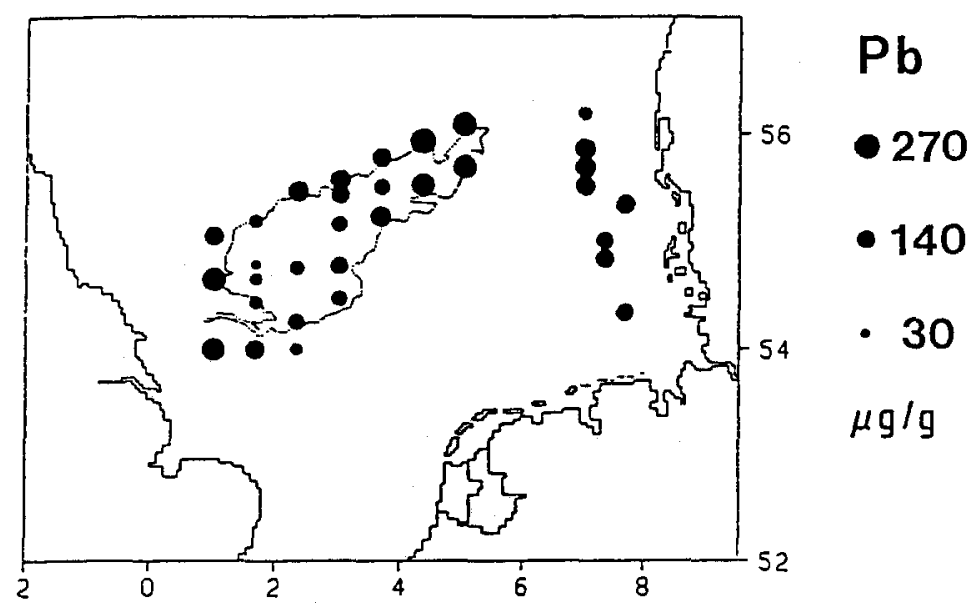

Fig. 1. Lead concentration distributions in North Sea sediments $<20 \mu \mathrm{m}$

no significant difference between the two areas of investigation, which could be confirmed by statistical analysis using notched box and whisker plots.

Results on the lead contents of macrofauna species published earlier by Kröncke (1987) showed in contrast to the results on lead contents in the sediment a significant difference between the two areas. A lower lead content was generally observed in the individuals taken from the eastern coastal area compared with those from the Dogger Bank, especially from its northeastern part. These results contradict the prevailing opinion that offshore invertebrate populations are, in comparison to individuals from coastal regions, less affected by contaminants such as heavy metals. The question arose whether this difference could be explained in terms of any sediment quality factor controlling the obviously different bioavailability of lead in these two areas, regarding the similar total amount of this toxic metal in the fine-grained fraction of the sediments.

\section{Correlations and regressions}

Previous investigations have shown that organic matter provides an important substrate for trace metals in North Sea sediments (Kersten \& Klatt, 1988). Table 2 depicts 
Table 2. Correlation matrix of metal concentration in sediment versus that in benthic organisms (n.s. = non-significant, $\mathrm{p}=0.05-0.001$ )

\begin{tabular}{|lcccc|}
\hline & TOC & $\mathrm{Pb}$ & $\mathrm{Pb} / \mathrm{TOC}$ & $\mathrm{Pb} / \mathrm{Fe}{ }^{*}$ \\
\hline $\mathrm{Pb}$ (Sediment) & 0.001 & & & \\
$\mathrm{~Pb}$ (Nephtys spp.) & 0.001 & 0.05 & n.s. & n.s. \\
$\mathrm{Pb}$ (E. cordatum) & n.s. & n.s. & n.s. & n.s. \\
$* 1 \mathrm{M} \mathrm{HCl}$ extractable & & & & \\
\hline
\end{tabular}

the highly significant positive correlation between lead and organic carbon, even though the variability of sedimentary environments represented in the entire data set of 32 samples of this study was neglected. The correlation coefficients can be improved, if the data of the two areas are analysed separately, indicating different regressions between lead and TOC.

If increasing metal concentrations in sediments are mostly due to a corresponding increase in the organic matter contained in the sediment, as indicated by the correlation results for lead, then the gradient method according to Cato (1977) may facilitate interpretation. The method is based on the relationship between the metal in question and the content of organic carbon using regression analysis. Cato (1977) proposed to use the gradient of the metal-TOC regression curve (i.e. the slope of the regression curve in Fig. 2a) as a measure of the contamination degree of a certain area assuming that most of the anthropogenic metal fraction in sediments is bound to organic matter. The steeper the gradient, the higher the level of heavy metal contamination. The differences in the metal contents at zero TOC concentrations ( $y$-axis intercept) between regressions from different areas can be interpreted as a function of the amount of metals coprecipitated by Fe/ Mn oxihydrates or held in the mineral lattices (i.e. the geological background). The slope of the regression, however, may be independent of the mean TOC concentration of the sediment, i.e. the compositional variations between different areas. In fact, the TOC median of the eastern North Sea samples is higher than that of the Dogger Bank samples (Table 1). On the other hand, the $\mathrm{Pb}$-TOC regression slope is twice as high for the Dogger Bank samples as that for the eastern North Sea sediments. According to this result, the Dogger Bank sediment quality with regard to lead contamination seems to be twice as bad as that of the coastal area of the eastern North Sea. This is in turn in good agreement with the contamination differences found in the benthic organisms of both areas.

This result points to a possible link between bioavailability and the organic fraction of lead in sediments, which is also supported by the significant positive correlation between lead content in polychaetes Nephtys spp. and TOC contents in the sediment samples (Fig. 2b). No correlation ( $p \leq 0.05$ ) has been found between total lead content in sediments and that in the polychaetes. In fact many authors have previously failed in their attempt to relate concentrations of contaminants in sediments to those in organisms. Most of them believe that within sediments, only specific chemical binding forms of contaminants are bioavailable (e.g. Campbell et al., 1988). For this reason, the sediments were subjected to more moderate extraction in order to leach the bioavailable metal portion only. Prompted by the somewhat improved correlations, and eager to find 

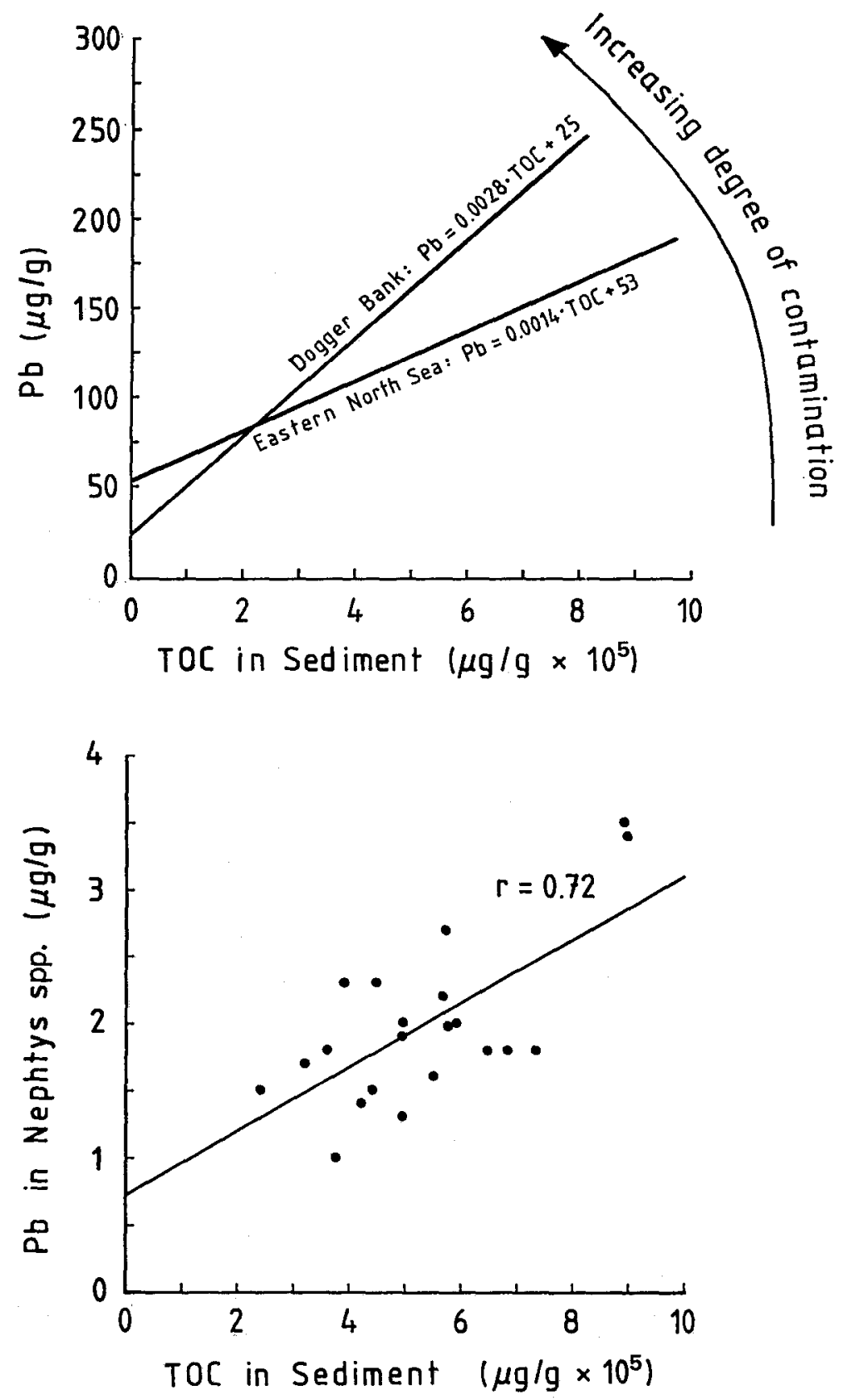

Fig. 2a, b. Regressions between TOC and Pb in sediments and organisms 
relations of predictive value, further research was focused on complexating sediment components. It was discovered that stronger correlations are found when the major complexing components like iron,. manganese, humic substances and total organic carbon of the sediments are taken into account. Iron oxihydrates, for example, are suggested to be in competition with biogenic mechanisms for metal uptake as predicted similarly for organic chelators in the water column. Luoma \& Bryan (1978) showed in an often cited study that the bioavailability of lead in sediment to the deposit-feeding clam Scrobicularia plana seems to decrease by the same amount by which the level of reactive (i.e. $1 \mathrm{M} \mathrm{HCl}$ extractable) iron in oxidized surface sediments increases. They showed that the ratio $\mathrm{Pb} / \mathrm{Fe}$ in $1 \mathrm{M} \mathrm{HCl}$ extracts may reflect availability of lead to the bivalve species, while correlation coefficients for $\mathrm{Pb}$-animal/Pb-sediment were found to be low. However, no improvement of correlation significance has been found using this ratio for our data (Table 2).

Some remarks are necessary in order to explain the low correlation between lead extracted chemically from sediment components and that extracted from the animals. Even if the metal portions extractable from sediments with varying geological and chemical characteristics are different, the metal content in benthic organisms can be similar or vice versa. This handicap is primarily due to a lack of information about the specific mechanism by which organisms actively translocate metals. Moreover, correlation analysis is further complicated by the polychaete's ability to actively regulate metal contents (Bryan 1985). Higher body concentrations might also be due to different growth rates of macrofauna species. It is known that offshore populations have a lower growth rate than nearshore ones because of lower temperatures and lower food supply (Buchanan, 1966; Duineveld \& Jenness, 1984). That would mean that offshore specimens with the same size as those from coastal waters have more time to accumulate metals. Also size frequency distributions for the ophiurids Amphiura filiformis and Ophiura albida by Künitzer (1989) show that individuals from stations north-east of the Dogger Bank are much older than those north-west of Helgoland. In contrast, current growth ring analyses for $O$. albida from the same samples by Dahm (pers. comm.) indicate no difference in growth and age between the individuals from the two areas of investigation. This would confirm that the higher toxicity of the Dogger Bank sediments results in higher lead contents of the biota.

\section{CONCLUSIONS}

Polychaetes (e.g. Nephtys spp.) dwelling in the sediments of two different areas of the North Sea show different degrees of lead uptake in contrast to the same total quantity of lead in the fine-grained sediment fraction. Thus, the use of total sediment metal concentration as well as non-residual metal fractions as a measure of the bioavailable concentration is not supported by the data available from this and other studies. It was shown, however, that an increasing slope in the regression between lead and organic carbon content in sediments corresponds with increasing toxicity of the sediments. This gradient method proposed by Cato (1977) as a sediment quality criterium seems to be an efficient and simple predictive tool to compare different areas. This result agrees well with the general observation that the only ingested sediment component that has the same effect on all sediment-dwelling organisms in all investigations is organic matter. 
The basic question whether and, if so, why contaminated sediment threatens the biotic environment, however, cannot be answered by our or other field surveys.

Acknowledgements. Thanks are due to Dr. G. Liebezeit for measuring the TOC-data and to C. Berger for correcting the English manuscript. This work was supported by grants from the German Ministry for Research and Technology (BMFT).

\section{LITERATURE CITED}

Bryan, G. W., 1985. Bioavailability and effects of heavy metals in marine deposits. In: Wastes in the ocean. Ed. by B. H. Ketchum, I. W. Duedall, J. M. Capuzzo, P. K. Park, W. V. Hurt \& D. R. Kester. Wiley, New York, 6, 41-77.

Buchanan, J. B., 1966. The biology of Echinocardium cordatum (Echinodermata: Spatangoidea) from different habitats. - J. mar. biol. Ass. U. K. 46, 97-114.

Campbell, P. G. C., Lewis, A. G., Chapman, P. M., Crowder, A. A., Fletcher, W. K., Imber, B., Luoma, S. N., Stokes, P. M. \& Winfrey, M., 1988. Biologically available metals in sediments. - CNRC Publ., Ottawa, 27694, 1-298.

Cato, I, 1977. Recent sedimentological and geochemical conditions and pollution problems in two marine areas in south-western Sweden. - Striae 6, 1-158.

Duineveld, G. C. A. \& Jenness, M. L., 1984. Differences in growth rates of the sea urchin Echinocardium cordatum as estimated by the parameter $w$ of the von Bertalanffy equation applied to skeletal rings. - Mar. Ecol. Prog. Ser. 19, 65-72.

Förstner, U., Ahlf, W., Calmano, W. \& Kersten, M., 1990. Sediment criteria development - contributions from environmental geochemistry to water quality management. In: Sediments and environmental geochemistry. Ed. by D. Heling, P. Rothe, U. Förstner \& P. Stoffers. Springer, Berlin, 311-338.

Kersten, M. \& Klatt, V., 1988. Trace metal inventory and geochemistry of the North Sea shelf sediments. - Mitt. geol.-paläontol. Inst. Univ. Hamburg 65, 289-311.

Künitzer, A., 1989. Factors affecting the population dynamics of Amphiura filiformis (Echinodermata: Ophiuroidea) and Mysella bidentata (Bivalvia: Galeommatacea) in the North Sea. In: Reproduction, genetics and distribution of marine organisms. Ed. by J. S. Ryland \& P. A. Tyler. Olsen \& Olsen, Fredensborg, 395-406.

Künitzer, A., 1991. Does settlement influence population dynamis of macrobenthos? A case study in the central North Sea. In: Population dynamics of marine organisms and eutrophication of the marine environment. Ed. by G. Colombo. Olsen \& Olsen, Fredensborg (in press).

Kröncke, I., 1987. Lead and cadmium content in selected macrofauna species from the Dogger Bank and the eastern North Sea. - Helgoländer Meeresunters. 41, 465-475.

Luoma, S. N. \& Bryan, G. W., 1978. Factors controlling the availability of sediment-bound lead to the estuarine bivalve Scrobicularia plana. - J. mar. biol. Ass. U.K. 58, 793-802. 